\title{
Occupational Health and Safety Status in the Management of Faecal Sludge in Ghana: A Case Study of the Lavender Hill Faecal Treatment Plant
}

\author{
Joseph Yeboah Siaw ${ }^{1}$, Issahaku Ahmed ${ }^{1,}$, , Dennis Ofori-Amanfo ${ }^{1}$, Florence Cobbold ${ }^{1}$, \\ Gizella Tetteh Agbotui ${ }^{1}$, Esi Awuah ${ }^{2}$ \\ ${ }^{1}$ Sewerage Systems Ghana Ltd., Accra, Ghana \\ ${ }^{2}$ Department of Civil Engineering, Kwame Nkrumah University of Science and Technology, Kumasi, Ghana \\ Email address: \\ yeboahsiaw@gmail.com (J. Y. Siaw), eagleskertozer@yahoo.co.uk (I. Ahmed), oblon13@hotmail.com (D. Ofori-Amanfo), \\ fcobbold@hotmail.com (F. Cobbold),gizella.ag@gmail.com (G. T. Agbotui), esiawuahrt@gmail.com (E. Awuah) \\ ${ }^{*}$ Corresponding author
}

\section{To cite this article:}

Joseph Yeboah Siaw, Issahaku Ahmed, Dennis Ofori-Amanfo, Florence Cobbold, Gizella Tetteh Agbotui, Esi Awuah. Occupational Health and Safety Status in the Management of Faecal Sludge in Ghana: A Case Study of the Lavender Hill Faecal Treatment Plant. Journal of Health and Environmental Research. Vol. 4, No. 2, 2018, pp. 42-50. doi: 10.11648/j.jher.20180402.11

Received: March 15, 2018; Accepted: March 30, 2018; Published: May 14, 2018

\begin{abstract}
Faecal sludge management in Ghana has been undertaken in different scales using different methods for years. Each of these methods involves human intervention in one form or the other. Direct human-to-faecal matter contact cannot be avoided completely in faecal sludge treatment. However, the degree of contact depends on the finesse of technology employed. Also, emission of gaseous substances along the treatment value chain both as a direct result of the sludge or of chemicals being employed in the treatment process is another challenge. In whichever way the situation is looked at, all these processes will present occupational safety and health issues to workers and other stakeholders if not proactively regulated. Data was collected at five different levels using different instruments at Lavender Hill Faecal Treatment Plant operated by Sewerage Systems Ghana Ltd. was analyzed for this study. This was done to ascertain the status of Health and Safety Practices and worker risk and or hazard exposures in a typical faecal management in Ghana. It was realised that a very comprehensive safety management systems have been instituted to ensure protection for all. Activities at the plant are regulated by an approved written health and safety policy, environmental management policy and standard operating procedures documents. Physical structures have safety warning signs fixed on them where appropriate and the plant's operations are supported with state-ofthe-art technology - gas detectors, buoyancy devices around open tanks, supply of appropriate personal protective equipment, provision of sanitary facilities among others. Management of the plant considers health and safety of every person admitted to the site an utmost priority. This is demonstrated by management's commitment to releasing funds and direct participation in safety programs. Awareness creation in the form of orientations and trainings is effectively communicated to all site patrons. Mental wellbeing of workers is ensured through a welfare system and a physical activity program. It is not surprising therefore that despite the extent of hazards associated with the faecal matter handling yet no serious incident, accident and or health related issues had yet been identified after more than a year of operation.
\end{abstract}

Keywords: Occupational Health and Safety, SSGL, Structural Development, Welfare System, Faecal Sludge Treatment

\section{Introduction}

Workers of health and safety at the workplace is provided for under the Labour Code of Ghana to be the responsibility of employers [1]. This is in view of the high rate of accidents recorded in the workplace. According to Labour Department of Ghana Annual Report in the year 2000 [2], a total of 8,692 accidents were work related accidents were reported for compensation claims. Apart from accidents occurring, the business of faecal sludge treatment presents its own challenges. Uncontrolled contact of faecal matter or any 
faecal matter laden material expose workers to a myriad of diseases [3]. Ensuring workers are safe from these hazards is compliant with international best practices. The introduction of the International Labour Organisation (ILO) constitution [4] which highlights the protection of the worker against sicknesses, diseases and injury arising out of employment is fundamental element of social justice. Occupational safety and health is human right and decent work eventually is safe work [5]. At the Lavender Hill Faecal Treatment Plant managed which is being managed by the Sewerage Systems Ghana Limited (SSGL), worker health and safety is considered a topmost priority by management. This is demonstrated by its commitment in terms of the provision of resources and the support of the activities of the Health, Safety and Environment (HSE) department. Worker engagement, education and training, and effective communication of safe work habits is a continuous effort at the treatment plant. In addition to the Lavender Hill Treatment plant, the company has other treatment plants [3].

According to the works of Asumeng in 2015 [6], Ghana does not have a national policy on occupational health and safety management as the ILO convention number 155 (1981) requires. There are however, the Labour Act 2003 (Act 561) [7], the Factories, Offices and Shops Act 1970, (Act 328) [8] and the Mining Regulations 1970 (LI 665) [9], which have some regulations about health and safety management at the work environment.

\section{Literature Review}

\section{History of Faecal/Sewage Treatment in Ghana}

Modern methods of treating faecal and sewerage in Ghana is very low as observed by UNICEF in 2016 [10]. The national average for sewerage coverage is as low as $4.5 \%$. Tema is the only municipality with a comprehensive sewerage system. Accra has a sewerage system covering the following areas: State House and ministries area, Dansoman and parts of the Central Business District with low property connections. There are also a number of satellite sewerage systems for Teshie-Nungua, Burma Camp, University of Ghana, Legon, Achimota School, 37 Military Hospital and Ridge areas. Most of These treatment facilities have broken down and not in use. The Mudor treatment plant, serving Dansoman/Korle $\mathrm{Bu}$ areas, Ministries, Flag Staff House etc. got broken down [10] but has been rehabilitated and being managed by Sewerage Systems Ghana Limited as part of its 3 current plants since 2017 [3].

Until recently, when the SSGL's Lavender Hill faecal treatment plant was commissioned, septage was directly discharged into the sea [11-12]. The consequences of this on the sea as a common property resource, the community in which the discharge point was located in terms of spread of diseases and odour was enormous. Upon the establishment of the Lavender Hill faecal treatment plant an average of about 200 cesspit emptiers dislodged at the plant every day [3].

Health and safety at work are considered to be very important issues as they are intrinsically linked with the overall well-being of working people [13]. The consequences of wastewater treatment hazards can be severe in terms of disposition to sicknesses. The probability of death occurring, even though small, is a reality. The consequences manifest in the cost of taking care of employees and attendant effect on machinery downtime and general productivity.

Not a significant percentage of people work in the waste water treatment industry. There does not appear to be any statistics on the phenomenon in the West African sub region since the treatment of faecal waste is still in the developmental stages. The risks involved are similar across some regions [14].

Due to the nature and characteristics of the faecal sludge being received at Lavender Faecal Treatment Plant (LFTP, the implementation of health and safety at the plant had been conceived as an inherent part of the plant right from the onset. Therefore, the roll out of health and safety operations started from ground zero, as it were. The establishment of structures and operation procedures started from the scratch and has since been developing gradually over the period. The development is even though not at the optimum as of now, it's making very giant strides towards the achievement of this noble goal. The SSGL's medium to long term objective of obtaining ISO certification in its operation adds impetus to its health and safety goals of achieving standards matching international best practices anywhere in the world.

\subsection{Laws Governing Occupational Health and Safety in Ghana}

Pieces of legislation introduced by government in the past have sought to protect the health, safety and welfare of all workers. These legislations include Factories, Shops and Offices Act of 1970 [8], Act 328 and Labour Act, 2003, Act 651 [7]. The Labour Act, for example, makes it obligatory for the employer to "ensure that every worker employed in Ghana works under satisfactory, safe and healthy conditions (Labour Act, 2003 Act 651, Article 118:1). Embedded in these laws are rights and obligation of both employers and employees. It is required for example that employees use the safety appliances, fire-fighting equipment and personal protective equipment provided by the employer

The employers' obligation under the Labour Act includes setting standards to safeguard the wellbeing of their employees, providing personal protection equipment, and providing necessary information, supervision and training consistent with the level of literacy of the employees.

The works of Asumeng and co-workers [6] noted that The Labour Act, 2003 Act 651 Act [7], is not specific on how to implement safety provisions at the organizational level and about whom to report accidents and occupational illnesses to. It is not even clear or does not specify what to consider as Occupational Illness. It does not specify who to be responsible for ensuring the industries in Ghana implement corrective actions as per recommendations. There is no national body, policy nor processes that govern occupational health and safety management in Ghana.

These gaping holes or lacuna in the law leaves the 
implementation of health and safety in many organisations in the country at the mercy of the benevolence of business owners. As result, workers who get involved in accidents and incidents at the workplace requiring the payment of compensation are either bullied to keep quiet, threatened dismissal or do not get any compensation at all.

Numerous injuries, illnesses, property damages and process losses take place at different workplaces but due to under reporting or misclassification due to lack or thorough standards, or unfamiliarity with the existing guidelines, people are not normally in the known of such events as well as their actual or potential consequences [6].

These loopholes notwithstanding, the operation of the Lavender Hill Faecal Treatment Plant is undertaken with human feeling and respect for basic rights of every human being to a decent job. Handling faecal matter in any shape or form ought to be considered beyond the ordinary and SSGL Management is very committed to this self-imposed obligation even when not being "watched" as it were. The commitment is demonstrated by the recruitment of professional health and safety personnel and the approval of a health and safety policy document by the board of directors. Occupational safety and health have been repeatedly mentioned as a fundamental right of every worker, and are referenced in the Alma Ata Declaration on Primary Health Care (1978) [15], the WHO constitution, the UN's Global Strategy on Health for All (2000) [16], the ILO Constitution [4] and in many other multilateral conventions and documents

\subsection{Occupational Hazards in the Faecal Treatment Industry}

The industry relies on septage trucks that visit individual homesteads to siphon septage. Back at the plant there is a complex mix of activities ranging from movement of cars, maintenance of plant equipment and machinery, civil works, pedestrian activities, offloading of septage, environmental cleaning, working around open liquid holding tanks, flaring of biogas, physico-chemical and microbiological laboratory analysis of the faecal sludge among others. Each of these activities present their own health associated risk and unique hazards.

These hazards are appreciated in their various forms and measures have been instituted to alleviate them. According to Mackay [17] the aim of any harm prevention strategy should be to have exposure to risk factors below a level which can cause harm. It is essential to note that hazards only represent potential to cause harm. Whether the harm actually occurs or not depends on circumstances, such as the toxicity of the health hazard, exposure amount, the extent of the risk factors present, and duration of exposure to the risk factors. The research work [17] indicates that preventive strategies have elements comprising both surveillance and control measures, and proper design of the preventive strategies require understanding about the relationships between hazard, harm and risk. There is theoretical and empirical evidence linking hazards to harms, through risk factors [18 - 20]. There is the need for understanding of these basic concepts: hazards, risks, and harm. Hazards according to the Ghana Ministry of Health-MOH (2010) refer to those features, either physical or psychosocial or a combination of both, of the workplace that have the potential to lead to harm or unwanted consequences. It is an inherent property of a substance, agent, source of energy or situation having the potential of causing considerable consequences. The likelihood that exposure to a hazard will lead to harm is technically referred to as risk. $\mathrm{MOH}$ (2010) [21] noted that risk represents: "The probability that damage to life, health, and/or the environment will occur as a result of a given hazard (such as exposure to toxic chemical)".

At the Lavender faecal treatment plant, the following key occupational safety and health hazards are identified. These are safety hazards, biological hazards, ergonomic hazards, chemical hazards and psychological hazards.

\subsection{Safety Hazards}

These are the most common and will be present in most workplaces at one time or another. Safety hazards include unsafe conditions that can cause injury, illness and death. They are the most common features of most workplace. These hazards include: spills on floors or tripping hazards, such as blocked aisles or cords running across the floor; working from heights, including ladders, scaffolds, roofs, or any raised work area; unguarded machinery and moving machinery parts; guards removed or moving parts that a worker can accidentally touch; electrical hazards like frayed cords, missing ground pins, improper wiring; confined spaces, machinery-related hazards (lockout/tagout; forklifts).

\subsection{Biological Hazards}

This type of hazards is associated with biological agents. At Lavender Hill these include pathogenic viruses, bacteria and helminths. These arise as a result of exposure to blood and other body fluids, fungi/mold, bacteria and viruses, insect bites, and contact with faecal matter. These have the potential of resulting in infections of various forms.

\subsection{Ergonomic Hazards}

These usually occur when the type of work, body positions and working conditions put strain on the worker's body. They are the hardest to spot since it is not always possible to immediately notice the strain on your body or the harm that these hazards pose. Short-term exposure may result in sore muscles the next day or in the days following exposure, but long-term exposure can result in serious long-term illnesses. Ergonomic Hazards include: improperly adjusted workstations and chairs, frequent lifting, poor posture, awkward movements, especially if they are repetitive, repeating the same movements over and over, having to use too much force, especially if you have to do it frequently, and vibration. 


\subsection{Chemical Hazards}

These are present when a worker is exposed to any chemical preparation in the workplace in any form (solid, liquid or gas). Some are safer than others, but to some workers who are more sensitive to chemicals, even common solutions can cause illness, skin irritation, or breathing problems. They include: Liquids like cleaning products, paints, acids, solvents.

\subsection{Psychological Hazards}

Psychosocial hazards are defined to include the interactions among job content, work organisation and management, and other environmental and organisational conditions, on the one hand, and the employees' competencies and needs on the other. Thus, psychological hazards refer to various forms of workplace interactions that have a hazardous influence over employees' health through their perceptions and experience (ILO, 1986) [4]. A psychological hazard is any hazard that affects the mental well-being or mental health of the worker and may have physical effects by overwhelming the individual's coping mechanisms and impacting the worker's ability to work in a healthy and safe manner [22]. Cox and Griffiths (2005) [23] also consider psychosocial hazards to be those aspects of the design and management of work, and the social and organisational contexts of work that have the potential for causing psychological or physical harm.

\section{Materials and Methods}

\subsection{Study Area}

All Cesspit trucks from Greater Accra and some parts of Eastern and Central Regions which is estimated to be 200 daily dislodged at the LHFTP. For this study, the Lavender Hill Faecal treatment plant where almost all the cesspit trucks dislodged was selected, it is located in James Town. This site or plant was selected because it is the first of its kind in the country and some part of Africa in faecal sludge treatment technology applications.

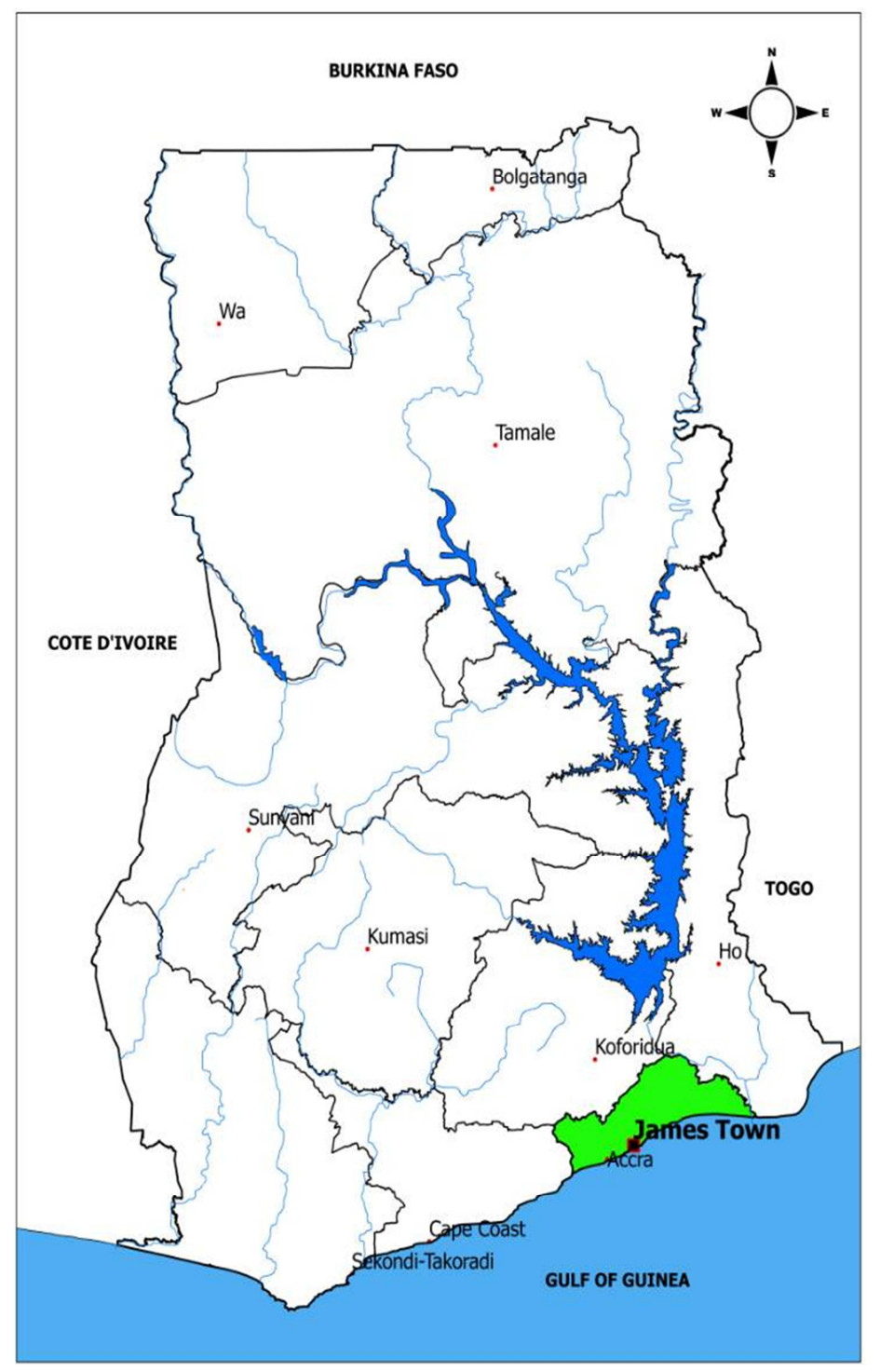

Figure 1. Study area, James-Town, Accra-Ghana. 


\subsection{Methodology}

The lavender hill faecal treatment plant employs a total of 102 staff made of 9 females and 93 males till date but there are more room for additional hands to be added in the near future. This is made of senior level managers, middle level technical personnel made up engineers and other professional's technicians and general plant attendants. The level of exposure to faecal matter differ and happen at different times with different exposure durations. Faecal treatment is specialised field which could potentially endanger life if not handled with care. Workers suffer different health related hazards. Management therefore is concerned and takes responsibility for every worker.

Data was collected at five different levels using different instruments:

1. Enumeration of health and safety structures installed or implemented since operation of the plant begun in December 2016 and still in operation. These include the status on:

i. Fire detecting and suppression/extinguishing mechanisms

ii. Physical safety structures - fall arrests, buoyancy devices and warning signs installed

iii. Mechanisms for detecting tolerable gases and other harmful substances levels/air quality analysis

iv. Safety committee meetings

v. Medical monitoring

vi. Physical activity program

vii. Sanitary methods

2. Number of personnel given safety induction, on the job training and participation in the continue training program of the company

3. Amount of personal protective equipment types and quantities procured and supplied with appropriate training on usage since beginning of the operations

4. The level of understanding and appreciation of health and safety consciousness of workers

5. Liaison with external auditing bodies on the company's activities reporting obligations.

A total of 32 workers, representing $31.4 \%$ of the entire workforce of SSGL were interviewed. Workers were selected randomly. Selected workers made up of a mix of old people who had been around since the inception of plant activities, those who joined somewhere mid-way and the very recent staff. Major health hazards considered included vulnerability, administrative changes and the level of knowledge. Observation techniques were also adopted to understand the major installations, vulnerable zones and risk factors at various places.

During the interview of workers, all data were recorded properly in a notebook. The collected data was manually coded according to the objective of the study.

All the collected data were summarized and examined carefully. Then data were made MS Excel sheet. The study also relied on secondary data for verification of facts and to comparison with previous works. Primary data are first-hand information collected through various methods such as observation, interviewing, key informant interview and focus group discussion. The observation methods were participated structured and controlled. The interview method of collecting data involved presentation of oral-verbal stimulating and reply in terms of oral-verbal personal response. Study also complete one focus group discussions (FGD).

Secondary sources of data and information included HSE departmental records, survey records, written documents, different relevant books, articles, reports, journals and research papers. The study reflects the general scenario of health and safety status of SSGL Lavender Hill site.

\section{Results and Discussion}

\subsection{Structural and Operational Developments}

The establishment of structures and operation procedures started from the scratch and has since been developing gradually over the period. The development is even though not at the optimum as of now, it's making very giant strides towards the achievement of this noble goal. Development of physical health and safety structures and procedures, development of orientation and training programs for stakeholders, personal protective equipment types and such related issues has been evolving. Since this type of innovation is new to this environment, the challenge to also innovate and think outside the box is a daily occurrence. Experiences of staff of the HSE department coupled with those of other experts/colleagues from diverse backgrounds of endeavour, especially in the engineering fields, collaborating has contributed immensely the achievement of the success story of Lavender Hill Faecal Treatment Plant today.

\subsection{Instituted Health and Safety Structures at Lavender Hill}

Since the inception of the operation of the LHFTP in December 2016, resources, time, effective consultation and collaboration and careful planning have resulted in the establishment of the following structures.

i. Health and safety policy documentation

ii. Fire detecting and suppression/extinguishing mechanisms

iii. Physical safety structures - fall arrests, buoyancy devices and warning signs installed

iv. Mechanisms for detecting tolerable gases and other harmful substances levels/air quality analysis

v. Safety committee meetings

vi. Medical monitoring

vii. Physical activity program

viii. Sanitary methods 
Table 1. Detail statistics on the instituted structures at Lavender Hill Faecal Treatment Plant.

\begin{tabular}{|c|c|c|c|}
\hline Name of Structure or Institution & Date of Establishment & Numbers Involved & Effectiveness Status \\
\hline $\begin{array}{l}\text { policy and standard operating procedures } \\
\text { documentation }\end{array}$ & December 2016 & $\begin{array}{l}\text { Safety policy and SOP } \\
\text { documents }\end{array}$ & Approved and operational at LHFTP \\
\hline $\begin{array}{l}\text { Fire detecting and suppression/extinguishing. } \\
\text { Three way panel fire detecting and alarm } \\
\text { system installed within the main office } \\
\text { building and different classes of fire } \\
\text { extinguishers (class A, B C and E) }\end{array}$ & $\begin{array}{l}\text { Since December } 2016 \\
\text { when plant started. } \\
\text { Others were added on } \\
\text { as new plant machinery } \\
\text { were commissioned. }\end{array}$ & $\begin{array}{l}\text { total of } 31 \text { fire } \\
\text { extinguishers of varying } \\
\text { weights made up of } 12 \\
\text { class A, } 15 \text { class B\&C } \\
\text { and } 4 \text { of class E }\end{array}$ & $\begin{array}{l}\text { These are serviced regularly and in good } \\
\text { maintenance order }\end{array}$ \\
\hline Fall arrests (harness and lanyard) & Dec-16 & 16 & all in good working order \\
\hline Buoyancy devices (life buoy) & Jan-18 & 18 & all in good working order \\
\hline $\begin{array}{l}\text { multi-gas detectors (combustible gases, } \\
\text { hydrogen sulphide, carbon monoxide and } \\
\text { oxygen) }\end{array}$ & Jun-17 & 3 & $\begin{array}{l}\text { All in good working order. This is supported by air } \\
\text { quality analysis by external consultants }\end{array}$ \\
\hline Alcohol tester & Jun-17 & 1 & good working condition \\
\hline Safety committee & Mar-17 & 1 & $\begin{array}{l}\text { Made up of representatives from all departments } \\
\text { and consultants of SSGL. The committee meets } \\
\text { once every month }\end{array}$ \\
\hline Medical monitoring & Nov-16 & all workers & $\begin{array}{l}\text { Pre-employment check-up, biannual mandatory } \\
\text { medical check-ups, immunisation in hepatitis B, } \\
\text { cholera, medical insurance for all staff }\end{array}$ \\
\hline Sanitation & Nov-16 & all workers & $\begin{array}{l}\text { Effective hand wash facilities, hand sanitizers, } \\
\text { footbaths provided at vantage points within plant. } \\
\text { Plant attendants receive toiletries with chemical } \\
\text { disinfectants, sanitizers for home every month. }\end{array}$ \\
\hline Physical activity program & Jan-18 & all workers & $\begin{array}{l}\text { Once a week hour allocated for physical body } \\
\text { exercise for all workers instituted to keep workers } \\
\text { healthy. }\end{array}$ \\
\hline
\end{tabular}

These physical and institutional structures working in concert have ensured the foundation is properly set to ensure effective implementation of health and safety.

\subsection{Man Power Development in Health and Safety at LHFTP}

At the LHFTP different categories of stakeholders are given orientation and training. These categories include staff of SSGL, contractors of the company and their assignees, septage truck operators and visitors. The visitor category is made up of people ranging from students in academic institutions to researchers to administrators in local government agencies and politicians.

\subsection{Safety Induction/Orientation}

For each category, visit to any part of the plant was preceded by a safety orientation or briefing and the provision of basic personal protective equipment normally made up of head, hands and feet protection. The challenge was always with septage truck emptier drivers who often ignored safety advice. This stemmed from the history of non PPE use which had become part of them. To them, business as usual as opposed to innovative ways which was the order of the day.

The table below details statistics on stakeholders that received orientation training since the incepting of plant operations at LHFTP.
Table 2. Stakeholder Induction/Orientation at LHFTP.

\begin{tabular}{lll}
\hline \multirow{2}{*}{ Category of trainees } & Year \\
\cline { 2 - 3 } & $\mathbf{2 0 1 6}$ & $\mathbf{2 0 1 7}$ \\
\hline Staff & 23 & 61 \\
Contractors & 4 & 8 \\
Septage truck operators & 56 & 205 \\
Visitors & 9 & 992 \\
Total & 88 & 1,258 \\
\hline
\end{tabular}

In all a total of one thousand six hundred and eighty-one (1681) stakeholders have received safety induction prior to a visit, to commence actual work schedule as staff or to commence a contract. Content of materials taught at each of these categories is different. The number trained in 2017 was one thousand two hundred and fifty-eight. This is significant in that it was the first full year of plant operations.

\subsection{Staff Training}

In addition to the induction or safety orientations preceding actual commencement of work, staff of SSGL undergo regular safety training. These trainings include training on emergency response, fire incidents and fighting, first aid, training on permits among others. Within the period special general staff were trained to become safety assistants. Training and retraining of staff was ensured staff safety obligations were fulfilled. Trainers were drawn from both internal expertise and externally. Liaison with external expertise also help develop strong bond with key institutions which tended to benefit SSGL.

Provision of Personal Protective Equipment 
Table 3. Data on PPE'S (types and quantities) procured and supplied with appropriate training on usage for the year 2017 at the plant.

\begin{tabular}{|c|c|c|c|c|c|c|c|c|c|c|c|c|c|c|}
\hline \multirow{2}{*}{ No. } & \multirow{2}{*}{ ITEM NAME } & \multicolumn{12}{|c|}{ Month } & \multirow{2}{*}{ Total } \\
\hline & & Jan & Feb & Mar & Apr & May & Jun & Jul & Aug & Sept & Oct & Nov & Dec & \\
\hline 1 & Disposable Hand Gloves (pairs) & 250 & 200 & 100 & 350 & 200 & 200 & 250 & 200 & 950 & 1100 & 1000 & 650 & 5450 \\
\hline 2 & $\begin{array}{l}\text { Nose Mask with filters EN } \\
\text { 149:2001/MG6AFFP2 }\end{array}$ & 50 & 28 & 8 & 37 & 48 & 96 & 31 & 28 & 70 & 98 & 340 & 160 & 994 \\
\hline 3 & Bathing Soap & & & & & & & 58 & 58 & 58 & 58 & 60 & 60 & 352 \\
\hline 4 & Hand Gloves with Nitrile inside & 19 & 20 & 15 & 19 & 25 & 13 & 13 & 45 & 59 & 38 & 50 & 20 & 336 \\
\hline 5 & Waterproof Gloves (Rubber) & & & & & & 39 & 47 & 40 & 59 & 39 & 21 & 40 & 285 \\
\hline 6 & Overall & 4 & 2 & 1 & 3 & 4 & 150 & 4 & 5 & 5 & 3 & 37 & 1 & 219 \\
\hline 7 & Key Soap & & & & & & & 29 & 29 & 29 & 58 & 30 & 30 & 205 \\
\hline 8 & Hand Sanitizer (200ml) & & & & & & & 1 & 15 & 12 & 95 & 5 & & 128 \\
\hline 12 & Liquid Antiseptic (Carmel 1000ml) & & & & 1 & 3 & 1 & & 29 & 1 & 58 & 3 & 2 & 98 \\
\hline 9 & Wellington Boot & & & 2 & 4 & & 35 & & & 13 & 10 & 21 & 3 & 88 \\
\hline 10 & Disposable Overall & & 8 & 15 & 21 & 10 & & & 5 & 7 & 6 & 6 & & 78 \\
\hline 11 & Leather Safety Boot & & & & & & 67 & & & 1 & 1 & 2 & & 71 \\
\hline 13 & Duster & 15 & 7 & & 4 & 13 & 2 & 8 & 4 & 4 & 6 & 7 & & 70 \\
\hline 14 & Rain Coat Overall & & & & & & 50 & & & & & & & 50 \\
\hline 15 & Wiper & 15 & & & & 10 & 1 & & 5 & 10 & & 5 & & 46 \\
\hline 16 & Safety Goggles & & & & 5 & 4 & 9 & 1 & & 16 & 3 & 2 & & 40 \\
\hline 35 & Shoe Covers & & 4 & & 4 & 3 & & 2 & 3 & 5 & & 10 & 2 & 33 \\
\hline 17 & Nose Mask with Respirators & & 2 & & 3 & 14 & 3 & & & & 3 & 5 & & 30 \\
\hline 18 & Disposable Nose Mask (box) & & 4 & & 4 & 3 & & 2 & & 5 & & 10 & 2 & 30 \\
\hline 19 & Hard Hat & 3 & 1 & 2 & & 3 & & 2 & & 12 & 2 & 3 & & 28 \\
\hline 20 & Safety Cones & 20 & & & & & & & & 2 & & & 3 & 25 \\
\hline 21 & Working Gear (Top \& Down) & & & & & & & & 4 & 7 & 5 & 3 & 1 & 20 \\
\hline 22 & Liquid Soap (5 Litres) & & & & & 1 & 3 & 3 & & 1 & 1 & 6 & 1 & 16 \\
\hline 23 & Full Face Shield & 13 & & & & & & 2 & & & & & & 15 \\
\hline 24 & Cartridge & & & & & & & & & & 15 & & & 15 \\
\hline 25 & Nose Mask NP 303/306 & & & 3 & 7 & 3 & & & & & & & & 13 \\
\hline 26 & Airstreme Fan & & & & & & & & & & 13 & & & 13 \\
\hline 27 & Dusk Mask & & & & & & 10 & & & & 2 & & & 12 \\
\hline 28 & CleanSan & 2 & & 3 & & 3 & & 3 & & & & 1 & & 12 \\
\hline 29 & Brushes and Brooms & & & & & 10 & & & & & & & 1 & 11 \\
\hline 30 & Reflective Jackets & & & & & 3 & & & & & 2 & 1 & 2 & 8 \\
\hline 31 & Half Face Shields & & & & 6 & 1 & & & & & & & & 7 \\
\hline 32 & Hand Sanitizer Refill (5Liters) & 1 & & & 1 & & & 1 & & 1 & & 1 & 1 & 6 \\
\hline 33 & Bucket & & 4 & & & & 1 & & & & & & 1 & 6 \\
\hline 42 & Live Jackets & 2 & 4 & & & & & & & & & & & 6 \\
\hline 34 & Ear Muffs & & & 2 & & & & & & & 3 & & & 5 \\
\hline 36 & Leather Gloves & & 2 & & & & & & & & & & & 2 \\
\hline 37 & Door Mat & & 1 & & & & & & & & & & 1 & 2 \\
\hline 38 & Waste Bin & & & & & 1 & & & & & & & & 1 \\
\hline 39 & Over Coat & & & & & 1 & & & & & & & & 1 \\
\hline 40 & Foot Bath Container & & & & & & & & & & & 1 & & 1 \\
\hline 41 & Dust Pan & & & & & & & & & & & & 1 & 1 \\
\hline
\end{tabular}

Forty-one different safety items applied in varied situations and circumstances were issued out. The table gives an idea of items most frequently used. The various types of nose and hand protection were the most consumed.

\subsection{Safety Consciousness of Workers}

Knowledge level of workers was tested with a simple random survey. A total of 32 workers, representing $31.4 \%$ of the entire workforce LHFTP were interviewed. Selected workers were made up of a mix of old personnel who had been at post since the inception of plant operation, those who joined somewhere mid-way and the very recent staff.

The personnel were divided into three equally-sized knowledge groups based on health and safety knowledge score. Respondents were then grouped by their Knowledge Level Score (KLS) into three groups namely:

i. Low knowledge - KLS of less than 10

ii. Medium knowledge - KLS of between 11 and 20

iii. High knowledge - KLS of between 21 and 30 .

Knowledge levels were tested on six main areas. These were types of hazards, donning and doffing of PPEs, awareness about first aid, response to emergency, basic hygiene and work around open liquid holding tanks. Each of these was allocate a maximum score of five (5) being highly knowledgeable and zero (0) being little or no knowledge at all. The results showed that majority $(53.1 \%$ of medium knowledge and $31.3 \%$ of high knowledge) of workers interviewed showed very satisfactory level of knowledge and 
consciousness about issues of health and safety. However, $15.6 \%$ fell within the low knowledge bracket.

These definitions (listed above) will be used as baseline to assess the level of knowledge of future knowledge groups to determine any variations. For example, this analysis will be compared to next year's data to see if knowledge levels within the categories will change within the workforce. The level of understanding and appreciation of health and safety consciousness of workers is an important parameter in determining the sort of training program to adopt. It is also a measure of performance of the HSE Department.

\subsection{Liaison with External Auditing Bodies}

Over the period of operation of the LHFTP, important state regulatory agencies have been involved in ensuring adherence to regulations and laws. Some of these organisations include the department of factories inspectorate Ghana national fire service, Environmental Protection Agency, Ghana National Ambulance Service and the Red Cross Society of Ghana. Collaboration has been in the areas of ensuring adherence to standards, advisement, training and provision of other services.

Beyond these, subscription to international journals on health and safety and membership of internationally recognised bodies on health and safety provide the platform for knowledge sharing and acquisition.

\section{Conclusion and Recommendation}

This study aimed to determine the current health and safety status of the Lavender Hill Faecal Treatment Plant in Accra Ghana. The focus has been on set up of health and safety structures - physical and institutional. The study has brought to the fore in a systematic manner the establishment and evolution and the implementation of safety principles to ensure the operational safety of all kinds of patrons of the plant. Chiefly among these are the workers who spend most of their productive time in the plant.

Workers are safe from most of the hazards identified on site. This is due to the level of alertness and consciousness level among workers. Malaria is the main disease that plague workers. This is evident from the medical records at the human resources department. Collection of water in poodles on site is being corrected with engineering controls. Mosquito repellents are supplied to workers who come on night shifts.

SSGL is building a culture of a very safe working environment for all patrons of its companies, LHFTP being the headquarters. The setting up of various structures and the systematic approach to awareness creation communicated in simple language is the vehicle for achieving this objective.

The provision of appropriate personal protective equipment meeting international standard ensure adequate protection is offered to workers in situations where PPE use is the last resort. An array of all hazard control measures are employed depending on the situation at hand.

Existing knowledge levels in health and safety of most workers from their previous places of work, even though, not applicable en bloc, is still useful since the basic safety precautions needed for a safe work to a large extend apply in most workplaces. This is more of the application of common sense.

The LHFTP cherishes its relationships with external organisations be they regulatory or for support and collaboration. The frontiers for more partners is being pushed to network relevant organisations to reap full benefits of synergy.

An important contribution from this study is that it is providing a baseline data for future wastewater treatment plants of this magnitude in the West African sub region. What is happening at lavender hill is an innovation the first of its kind in the whole sub region. Subsequent plants may not have to reinvent the wheel. The LHFTP did not have the advantage of such data.

\section{Acknowledgements}

The authors would like to extend their profound gratitude to all workers of Sewerage Systems Ghana Ltd., the Executive Chairman (EC) of the Jospong Group of Companies (JGC), as well as the Board and Management of Sewerage Systems Ghana Ltd.

\section{References}

[1] Occupational safety and health country profile: Ghana. Found at: http://www.ilo.org/legacy/english/inwork/cb-policyguide/ghanalabouract2003section109.pdf

[2] Department of Ghana Annual Report in the year 2000. Cited in Maxwell Asumeng, Lebbaeus Asamani, Joana Afful and Collins Badu Agyemang. 2015. Occupational safety and health issues in Ghana: strategies for improving employee safety and health at workplace.

[3] Issahaku Ahmed, Ama Mbeaba Quarshie, Dennis OforiAmanfo, Florence Cobbold, Eric Simon Amofa-Sarkodie, Esi Awuah. Assessment of Foreign Material Load in the Management of Faecal Sludge in the Greater Accra Region of Ghana. International Journal of Energy and Environmental Science. Vol. 3, No. 1, 2018, pp. 27-36. doi: 10.11648/j.ijees.20180301.13

[4] ILO Constitution. 1944. Found at: http://blue.lim.ilo.org/cariblex/pdfs/ILO_Constitution.pdf

[5] http://www.who.int/occupational_health/publications/healthy_ workplaces_model_action.pdf

[6] Asumeng M, Asamani L, Afful J and Badu Agyemang C. 2015. Occupational safety and health issues in Ghana: strategies for improving employee safety and health at workplace.

[7] Ghana Labour Act 2003. 2003. Found at: http://www.ilo.org/legacy/english/inwork/cb-policyguide/ghanalabouract2003section109.pdf

[8] Factories, Offices and Shops Act 1970. 1970. Found at: http://www.melr.gov.gh/wpcontent/uploads/2015/11/Factories-and-Shops-Act.pdf 
[9] Mining Regulations 1970. Cited in Occupational Health and Safety and Organizational Commitment: Evidence from the Ghanaian Mining Industry. Found at: https://ac.elscdn.com/S2093791116000032/1-s2.0-S2093791116000032main.pdf? tid=4d069cae-04d1-4f09-8af9$\mathrm{d} 8 \mathrm{~b} 3 \mathrm{db} 52 \overline{7} 5 \mathrm{bd} \& \mathrm{acdnat}=1520864960 \_49 \mathrm{da} 1$ ef1 $7396 \mathrm{f} 9804 \mathrm{cf} 7$ $\mathrm{d} 74 \mathrm{a} 7 \mathrm{fba} 50 \mathrm{db}$

[10] UNICEF. 2016. Assessment of Waste Water Treatment Plants In Ghana. Pp 18

[11] Doku A. I. (2003) The potential for the use of upflow anaerobic sludge blanket (UASB) reactor for the treatment of faecal sludges in Ghana (BSc (Kumasi), MSc (Leeds), MASc (Toronto), $\mathrm{PhD}$ (Leeds).

[12] Gbenatey, N. E. (2013). Faecal Sludge Reuse in Urban and Peri-urban Crop Production.

[13] Akhter, S., Salahuddin, A. F. M., Iqbal, M., Malek, A., \& Jahan, N. (2010). Health and occupational safety for female workforce of garment industries in Bangladesh, m(1), 65-70.

[14] Md. Mahmudul Hasan, Ruma Khanam, A. K. M. Mostafa Zaman, Md. Ibrahim. Occupational Health and Safety Status of Ongoing Construction Work in Patuakhali Science and Technology University, Dumki, Patuakhali. Journal of Health and Environmental Research. Vol. 3, No. 5, 2017, pp. 72-83. doi: 10.11648/j.jher.20170305.11

[15] Alma Ata Declaration on Primary Health Care (1978). Found at: http://www.who.int/publications/almaata_declaration_en.pdf

[16] UN's Global Strategy on Health for All (2000). Found at: http://iris.wpro.who.int/bitstream/handle/10665.1/6967/WPR RC032_GlobalStrategy_1981_en.pdf
[17] Mackay, C. J, Cousins, R., Peter J. Kelly, P. J., Lee, S., and Mccaig, R. H. (2004). Management Standards' and WorkRelated Stress in the UK: Policy Background and Science, Work and Stress, 18 (2), 91-112

[18] McEwan, B. S. (2000). The neurobiology of stress: From serendipity to clinical relevance. Brain Research, 886, 172189.

[19] Brunner, E. (2002). Stress mechanisms in coronary heart disease. In S. Stansfeld and M. Marmot (Eds.), Stress and the Heart: Psychosocial Pathways to Coronary Heart Disease (pp. 181-199). London: BMJ Books.

[20] Sapolsky, R. (2003). Taming stress. Scientific American, 289(3), 86-95. The Health Foundation (2011). Measuring safety culture, The Evidence Scan. London, the Evidence Centre. Retrieved from www.health.org.uk on February 10, 2015.

[21] Ministry of Health/Ghana Health Service (2010). Occupational Health and Safety policy and guidelines for the health sector, Ghana, GHS.

[22] Government of Alberta (2011). Best practices for the assessment and control of psychological hazards, (Vol 5) retrieved on March 12, 2018 from www.employment.alberta.ca/ohshealthcare

[23] Cox, T., \& Griffiths, A. (2005). The nature and measurement of work-related stress: theory and practice. In J. R. Wilson \& N. Corlett (Eds.), Evaluation of Human Work ( $3^{\text {rd }}$ ed.). London: CRS Press. 